\title{
Efektivitas Penggunaan Media Peraga Ikonik Jangka Sorong dan Mikrometer Sekrup Terhadap Pemahaman Konsep Pengukuran Siswa
}

\author{
Nurhasan Ropi i \\ Prodi Pendidikan Fisika, Program Pascasarjana, Universitas Negeri Semarang \\ JI Kelud Utara III, Semarang, Jawa Tengah, Indonesia - 50237 \\ E-mail : nurhasanropii@gmail.com
}

\begin{abstract}
Abstrak
Pembelajaran pada konsep pengukuran menggunakan jangka sorong dan mikrometer sekrup yang dilaksanakan di kelas, umumnya terkendala oleh jumlah alat ukur yang terbatas dan skala alat ukur yang relatif kecil, sehingga pemahaman siswa pada konsep pengukuran belum tercapai secara maksimal. Oleh karena itu, diperlukan media peraga ikonik jangka sorong dan mikrometer sekrup dalam pembelajaran sebagai media alternatif bantu yang lebih fleksibel untuk meningkatkan pemahaman siswa pada konsep pengukuran. Penelitian bertujuan untuk mengetahui peningkatan pemahaman siswa pada konsep pengukuran setelah digunakan media peraga ikonik jangka sorong dan mikrometer sekrup. Penelitian menggunakan metode eksperimen dengan desain Pretest-Postest Control Group Design. Penelitian dilaksanakan di kelas VII SMP Negeri 1 Banjarharjo dengan kelas VII A sebagai kelompok eksperimen dan kelas VII B sebagai kelompok kontrol. Data pemahaman konsep pengukuran diambil dari hasil tes awal dan tes akhir kedua kelompok. Hasil analisis data menunjukkan rata-rata skor pemahaman kelompok eksperimen saat tes awal 38,13 dan tes akhir 69,58 dengan ketuntasan individual $69,44 \%$ serta faktor gain 0,51, sedangkan rata-rata skor pemahaman kelompok kontrol saat tes awal 26,15 dan tes akhir 59,72 dengan ketuntasan individual 41,67\% serta faktor gain 0,45 . Penggunaan media peraga ikonik jangka sorong dan mikrometer sekrup efektif meningkatkan pemahaman siswa pada konsep pengukuran.
\end{abstract}

Kata kunci: efektivitas, media peraga ikonik, pemahaman konsep pengukuran

\begin{abstract}
The limited number of measuring devices generally becomes an obstacle of learning on measurement using Vernier caliper and micrometer screw in class. This situation causes students' achievement on measurement have not been maximum. Iconic vernier calipers and micrometer screw are needed in the learning as more flexible alternative auxiliary media to increase students' understanding on measurement concepts. The objective of this research is to determine the increase of students' understanding on the measurement concept after using the vernier calipers and micrometer screw iconic media. The research method used was an experimental method with the design of Pretest-Postest Control Group Design. The research was conducted in class VII of a junior high school in Banjarharjo. The experimental group was class VII A, while the control group is class VII B. The data of students' understanding on the concept of measurement was taken from the results of the posttest of both groups. The analysis results shows average score of experimental group understanding is 69.58 with $69,44 \%$ of individual completeness and 0.51 gain factor. Meanwhile, the average score of control group understanding is 59.72, with $41.67 \%$ individual completeness and 0.45 gain factor score. This study indicates that the use of vernier calipers and micrometer screw iconic media is effective in increasing the students' understanding on measurement concept of students.
\end{abstract}

Keywords: effectiveness, iconic media, the understanding on measurement concept

\section{PENDAHULUAN}

Perkembangan dunia pendidikan abad
21 yang cepat, memacu sekolah untuk menerapkan pola pendidikan yang bersifat dinamis dan berkesinambungan pada berbagai bidang. Salah satu upaya yang 
dilakukan dengan memanfaatkan perkembangan media dalam kegiatan pembelajaran. Pemanfaatan media dapat mendukung berlangsungnya pembelajaran yang interaktif antara siswa dan guru. Media pembelajaran dapat meningkatkan hasil belajar siswa (Fajriah dan Churiyah, 2016).

Media pembelajaran dapat berupa media peraga enaktif maupun media peraga ikonik. Media peraga enaktif merupakan media peraga sebenarnya yang digunakan dalam pembelajaran dan biasanya berbentuk tiga dimensi. Media peraga ikonik merupakan media peraga dalam bentuk ikon atau gambar visual bergerak ataupun tidak bergerak sesuai dengan bentuk alat peraga sebenarnya. Penggunaan media atau alat peraga dalam proses pembelajaran tidak hanya sebagai alat bantu mengajar, tetapi sebagai bagian integral dalam proses pembelajaran (Firdaus, 2018). Penggunaan media peraga dalam pembelajaran dapat meningkatkan minat dan perhatian siswa untuk belajar karena adanya unsur keaktifan dan unsur keterlibatan siswa dalam pembelajaran.

Penggunaan media peraga dalam pembelajaran sangat membantu efektivitas dan efisiensi penyampaian pesan dan isi pelajaran. Media peraga berguna agar bahan pelajaran yang disampaikan guru lebih mudah dipahami siswa serta memberikan pengertian konsep yang sebenarnya secara realistis. Penggunaan media alat peraga dapat meningkatkan pemahaman konsep dan hasil belajar fisika siswa (Riyanti, Sutikno dan Masturi, 2015). Penelitian yang dilakukan Mu`min (2015) melalui penerapan model pendekatan kontekstual berbantuan media peraga ikonik berupa simulasi virtual terbukti efektif meningkatkan pemahaman konsep siswa pokok bahasan gerak melingkar beraturan. Salah satu konsep fisika yang berkaitan dengan penggunaan media alat peraga adalah konsep pengukuran. Pengukuran dalam fisika berkaitan dengan kegiatan mengukur yaitu membandingkan suatu besaran dengan besaran sejenis yang dipakai sebagai satuan (Widodo, W. dkk, 2016). Pengukuran dilakukan menggunakan alat ukur sesuai dengan besaran yang akan diukur. Pengukuran besaran panjang dapat dilakukan menggunakan alat ukur antara lain: mistar, jangka sorong, dan mikrometer sekrup. Hasil observasi dengan rekan sejawat guru IPA di SMP Negeri 1 Banjarharjo kabupaten Brebes menunjukkan bahwa ratarata pemahaman siswa pada konsep pengukuran masih rendah. Hal ini ditunjukkan dengan banyaknya siswa yang keliru dalam melakukan pengukuran dan menuliskan hasil serta satuan pengukuran. Hasil rata-rata tes materi pengukuran siswa kelas VII A sampai kelas VII I tahun 2017/2018 masih dibawah kriteria ketuntasan minimal yang ditetapkan yakni 70 . Persentase ketuntasan siswa kelas VII mencapai $16,67 \%$. Guru mengalami kesulitan dalam menjelaskan konsep pengukuran kepada siswa karena terkendala oleh skala alat ukur yang relatif kecil dan jumlah alat ukur yang terbatas. Alat ukur jangka sorong dan mikrometer sekrup yang relatif kecil menyebabkan siswa mengalami kesulitan dalam mengamati skala alat ukur saat melakukan pengukuran sehingga siswa kurang maksimal dalam memahami konsep pengukuran. Solusi yang dapat digunakan untuk menjelaskan konsep pengukuran kepada siswa adalah dengan menggunakan media peraga jangka sorong dan mikrometer sekrup ikonik dalam pembelajaran yang bertujuan agar pemahaman siswa pada konsep pengukuran tercapai.

Media peraga ikonik yang digunakan menggunakan bentuk gambar visual interaktif melalui software pembelajaran. Alat peraga jangka sorong dan mikrometer sekrup divisualkan sedemikian rupa dari bentuk, bagian alat peraga, fungsi dan langkahlangkah penggunaan alat peraga. Visualisasi media peraga ikonik yang ditampilkan dalam software pembelajaran dapat digunakan secara interaktif oleh siswa dengan harapan pemahaman siswa terhadap konsep pengukuran tercapai maksimal.

\section{METODE/EKSPERIMEN}

Penelitian dilaksanakan dengan metode eksperimen. Populasi penelitian yang digunakan adalah seluruh siswa kelas VII 
semester 1 SMP Negeri 1 Banjarharjo tahun 2018/2019 yang terdiri dari 9 kelas. Sampel penelitian yang digunakan adalah kelas VII A sebagai kelompok eksperimen dan kelas VII B sebagai kelompok kontrol. Pembelajaran Kelompok eksperimen dilakukan dengan pemberian perlakuan pembelajaran menggunakan media peraga ikonik jangka sorong dan mikrometer sekrup dalam bentuk software pembelajaran sedangkan pembelajaran pada kelompok kontrol dilakukan secara konvensional. Penelitian menggunakan desain eksperimen tes awal dan tes akhir (Pretest-Postest Control Group Design) yang disajikan pada Tabel 1 (Sugiyono, 2016).

Tabel 1. Bagan Desain Penelitian Tes Awal dan Tes Akhir

\begin{tabular}{lccc}
\hline \multicolumn{1}{c}{ Sampel } & $\begin{array}{c}\text { Kondisi } \\
\text { Awal }\end{array}$ & Perlakuan & $\begin{array}{c}\text { Kondisi } \\
\text { Akhir }\end{array}$ \\
\hline K.eksperimen & $\mathrm{O}_{1}$ & $\mathrm{X}$ & $\mathrm{O}_{2}$ \\
K.kontrol & $\mathrm{O}_{3}$ & & $\mathrm{O}_{4}$ \\
\hline
\end{tabular}

Pengumpulan data menggunakan metode dokumentasi dan metode tes. Metode dokumentasi digunakan untuk mengumpulkan daftar nama siswa, dan daftar skor tes awal siswa saat dilakukan penelitian. Metode tes digunakan untuk mengukur pemahaman siswa tentang materi pengukuran. Tes yang digunakan adalah tes objektif bentuk pilihan ganda dengan 4 pilihan jawaban.

Data yang terkumpul dianalisis melalui dua tahap. Analisis tahap awal dilakukan untuk mengetahui apakah kedua kelompok mempunyai keadaan awal yang sama atau tidak. Uji yang dilakukan adalah uji kesamaan dua varian dan uji normalitas menggunakan data skor tes awal materi pengukuran. Analisis tahap akhir dilakukan menggunakan data skor tes akhir materi pengukuran. Tahapan analisis meliputi: uji normalitas, uji kesamaan dua varian, uji hipotesis, uji ketuntasan hasil belajar dan uji normal gain (Wiyanto, 2008).

\section{HASIL DAN PEMBAHASAN}

\section{Hasil tes pemahaman awal dan akhir}

Pembelajaran pada kelompok eksperimen, siswa dan guru melaksanakan pembelajaran secara interaktif menggunakan media peraga ikonik melalui software pembelajaran. Tampilan media ikonik jangka sorong dan micrometer sekrup dibuat mirip sebagai representasi dari alat peraga yang sebenarnya. Kemudian siswa diberi kesempatan berinteraksi langsung dalam kelompok dengan alat peraga sebenarnya setelah belajar melalui media peraga ikonik. Kemudian siswa yang terbagi dalam beberapa kelompok melanjutkan kegiatan pengukuran menggunakan alat ukur jangka sorong dan mikrometer sekrup sesuai dengan panduan LKS. Pembelajaran pada kelompok kontrol, siswa diajar oleh guru mata pelajaran menggunakan alat peraga jangka sorong dan mikrometer sekrup sebenarnya tanpa bantuan media peraga ikonik dalam pembelajaran. Data hasil tes pemahaman awal dan akhir antara kelompok eksperimen dan kelompok kontrol disajikan pada Tabel 2.

Tabel 2. Rekapitulasi hasil tes pemahaman awal dan akhir penelitian antara kelompok eksperimen dan kelompok kontrol.

\begin{tabular}{|c|c|c|c|c|c|}
\hline \multirow{2}{*}{ No } & \multirow{2}{*}{ Kriteria } & \multicolumn{2}{|c|}{$\begin{array}{c}\text { Kelompok } \\
\text { Eksperimen }\end{array}$} & \multicolumn{2}{|c|}{$\begin{array}{l}\text { Kelompok } \\
\text { Kontrol }\end{array}$} \\
\hline & & $\begin{array}{l}\text { Tes } \\
\text { Awal }\end{array}$ & $\begin{array}{l}\text { Tes } \\
\text { Akhir }\end{array}$ & $\begin{array}{l}\text { Tes } \\
\text { Awal }\end{array}$ & $\begin{array}{l}\text { Tes } \\
\text { Akhir }\end{array}$ \\
\hline 1 & Rata-rata & 38,13 & 69,58 & 26,15 & 59,72 \\
\hline 2 & $\begin{array}{l}\text { Skor } \\
\text { tertinggi }\end{array}$ & 70 & 100 & 50 & 75 \\
\hline 3 & $\begin{array}{l}\text { Skor } \\
\text { terendah }\end{array}$ & 20 & 35 & 10 & 40 \\
\hline 4 & $\begin{array}{l}\text { Hasil uji } \\
\text { hipotesis }\end{array}$ & \multicolumn{4}{|c|}{$\begin{array}{c}\text { thitung } 3,33>\text { ttabel } 1,99 \\
\text { Berbeda secara signifikan }\end{array}$} \\
\hline
\end{tabular}

Penggunaan bantuan media peraga ikonik jangka sorong dan mikrometer sekrup dalam pembelajaran memberikan pengaruh terhadap pemahaman siswa pada pokok bahasan pengukuran. Hasil uji t menunjukkan bahwa terdapat perbedaan rata-rata pemahaman antara kelompok eksperimen dan kelompok kontrol. Kesimpulan ini menunjukkan bahwa penggunaan media peraga ikonik jangka sorong dan mikrometer sekrup dalam pembelajaran memberikan efek 
terhadap peningkatan pemahaman siswa pada konsep pengukuran.

\section{Hasil ketuntasan belajar siswa}

Pembelajaran dikatakan efektif jika memenuhi syarat ketuntasan belajar. Seorang siswa dipandang tuntas belajar apabila siswa tersebut mampu menyelesaikan, menguasai kompetensi dan tujuan pembelajaran minimal $70 \%$ dari seluruh tujuan pembelajaran atau telah mencapai nilai standar yaitu telah mencapai daya serap lebih dari atau sama dengan 70. Ketuntasan klasikal dicapai jika jumlah siswa yang mampu menyelesaikan atau mencapai minimal $70 \%$, sekurangkurangnya $85 \%$ dari jumlah peserta didik di dalam kelas tersebut (Mulyasa, 2002). Data ketuntasan belajar antara kelompok eksperimen dan kelompok kontrol disajikan pada Gambar 1.

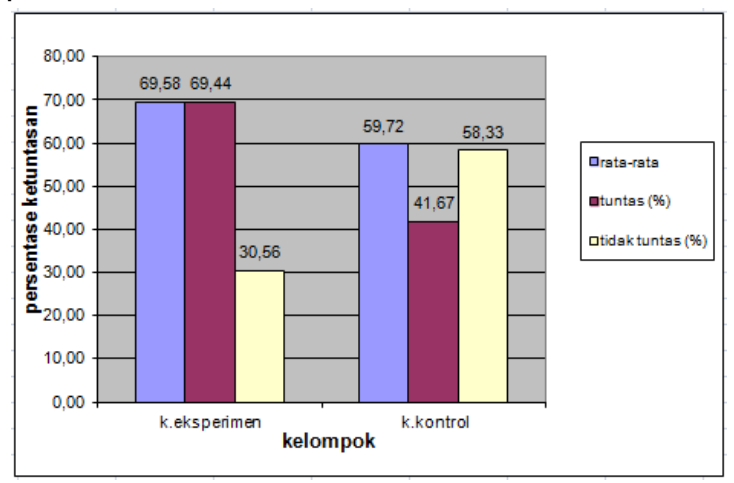

Gambar 1. Grafik ketuntasan belajar antara kelompok eksperimen dan kelompok kontrol.

Gambar 1 menunjukkan bahwa kelompok eksperimen dan kelompok kontrol belum mencapai ketuntasan belajar secara klasikal (keberhasilan kelas) karena ketuntasan individual tiap kelompok belum mencapai $85 \%$ dari keseluruhan kelas. Akan tetapi, ketuntasan individual dari kelompok eksperimen lebih baik dari kelompok kontrol. Hal ini dilihat dari jumlah siswa kelompok eksperimen yang memperoleh nilai 70 atau lebih berjumlah 25 siswa dari 36 siswa atau mencapai ketuntasan individual sebesar $69,44 \%$ sedangkan siswa dari kelompok kontrol yang mendapat nilai 70 atau lebih berjumlah 15 siswa dari 36 siswa atau mencapai ketuntasan individual sebesar $41,67 \%$. Kesimpulannya, pembelajaran pada kelompok eksperimen menggunakan alat peraga lebih efektif dibandingkan pembelajaran pada kelompok kontrol. Hal ini sejalan dengan penelitian yang dilakukan Misbah, dkk (2017) menggunakan media power point model pop up yang menyatakan skor rata-rata hasil belajar siswa yang diajar menggunakan bantuan media peraga lebih tinggi dari skor rata-rata hasil belajar siswa yang jarang diajar guru menggunakan media peraga.

\section{Hasil faktor gain peningkatan rata-rata pemahaman siswa}

Untuk mengetahui rata-rata peningkatan skor pemahaman konsep pengukukran antara kelompok eksperimen dan kelompok kontrol digunakan uji normal gain yang hasilnya disajikan pada Gambar 2.

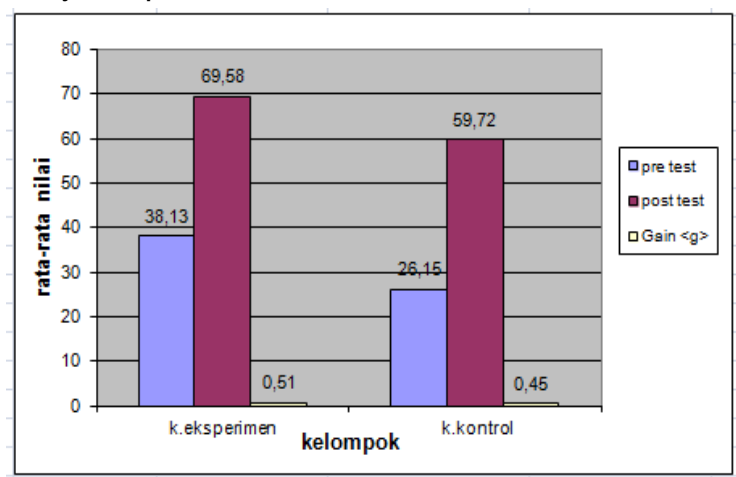

Gambar 2. Grafik rata-rata peningkatan pemahaman konsep pengukuran antara kelompok eksperimen dan kelompok kontrol.

Gambar 2 menunjukkan bahwa rata-rata peningkatan pemahaman kelompok eksperimen secara signifikan dapat dilihat dari rata-rata skor tes awal dan tes akhir yang diperoleh yaitu sebesar 38,13 dan 69,58 dengan faktor gain sebesar 0,51 sedangkan rata-rata peningkatan pemahaman pada kelompok kontrol secara siginfikan dapat dilihat dari rata-rata skor tes awal dan tes akhir yang diperoleh yaitu sebesar 26,15 dan 59,72 dengan faktor gain sebesar 0,45. Akan tetapi, peningkatan rata-rata pemahaman kelompok eksperimen lebih tinggi dari peningkatan ratarata pemahaman kelompok kontrol. Hal ini menunjukan bahwa penggunaan media peraga ikonik efektif dalam meningkatkan pemahaman siswa pada konsep pengukuran. Kesimpulan ini diperkuat oleh Aminulloh \& 
Widodo (2018) melalui penggunaan alat peraga bunyi yang menyatakan bahwa alat peraga bunyi efektif dalam meningkatkan motivasi dan pemahaman konsep siswa.

Penggunaan media peraga ikonik jangka sorong dan mikrometer sekrup dalam pembelajaran pada kelompok eksperimen dikatakan efektif secara individual karena lebih dari $50 \%$ siswa telah mencapai ketuntasan secara individual. Skor tes akhir tertinggi pada kelompok eksperimen mencapai 100. Hal ini menunjukkan bahwa alat peraga memungkinkan pembelajaran lebih sesuai dengan perorangan yang mana siswa belajar dengan banyak kemungkinan dan sumbersumber sehingga belajar berlangsung lebih menyenangkan bagi masing-masing perorangan. Saat pembelajaran berlangsung, seluruh siswa memusatkan perhatiannya pada media peraga, sehingga masing-masing siswa mempunyai cara-cara sendiri dalam menangkap dan memahami konsep pengukuran yang dipelajari melalui alat peraga.

Saat pembelajaran berbantuan media peraga ikonik berlangsung, siswa menjadi lebih tertarik dan termotivasi dalam belajar karena berinteraksi langsung dengan sesuatu yang baru dilihatnya. Motivasi siswa muncul setelah melihat kemudahan dalam mempelajari konsep pengukuran melalui media peraga ikonik. Motivasi siswa berkembang menjadi rasa penasaran, rasa ingin tahu, dan rasa ingin memahami tentang apa yang sebenarnya dapat dipelajari melalui media peraga tersebut. Siswa akan belajar lebih giat apabila topik yang dipelajarinya menarik dan berguna bagi dirinya (Mulyasa, 2002). Siswa SMP kelas VII dapat dikatakan merupakan peralihan dari masa kanak-kanak ke masa remaja sehingga hal-hal yang bersifat sesuatu yang baru dalam pembelajaran menjadi pemicu semangat dan motivasi siswa dalam belajar.

Penggunaan bantuan media peraga ikonik dalam pembelajaran memungkinkan perhatian dan konsentrasi siswa menjadi lebih terfokus karena siswa dapat berinteraksi langsung melalui media peraga ikonik. Siswa juga menjadi lebih tahu mengenai bagian- bagian, tingkat ketelitian, fungsi maupun kegunaan jangka sorong dan mikrometer sekrup karena selain melihat langsung alat ukur, juga diperjelas melalui media peraga ikonik. Saat pembelajaran, guru dan siswa mendemonstrasikan kegiatan pengukuran menggunakan alat peraga setelah belajar melalui media peraga ikonik. Guru menuntun siswa dalam belajar melalui pertanyaanpertanyaan yang diajukan saat kegiatan pembelajaran menggunakan media peraga ikonik berlangsung. Siswa tidak hanya aktif melihat maupun memperagakan alat peraga dalam pembelajaran, tetapi siswa juga aktif memikirkan, mengolah proses itu dalam pikirannya dan mengambil kesimpulan dari apa yang telah dipelajari. Melalui kegiatan demonstrasi dan diskusi kelompok, siswa lain yang memperhatikan menjadi lebih tahu dan paham dalam mempraktikkan kegiatan pengukuran langsung dengan menggunakan alat ukur jangka sorong dan mikrometer sekrup sesuai dengan panduan LKS yang tersedia. Melalui penggunaan media peraga ikonik jangka sorong dan mikrometer sekrup dapat membantu pembelajaran menjadi lebih efektif, efisien, dan menyenangkan karena dapat memberi motivasi kepada siswa dalam belajar serta dapat meningkatkan pemahaman siswa pada pokok bahasan pengukuran. Hal ini sejalan dengan pendapat Hadi (2017) yang menyatakan media peraga ikonik bentuk video efektif dalam meningkatkan motivasi dan hasil belajar siswa.

\section{PENUTUP}

Penggunaan media peraga ikonik jangka sorong dan mikrometer sekrup dalam pembelajaran efektif dalam meningkatkan rata-rata pemahaman siswa pada konsep pengukuran. Hal ini ditunjukkan dengan perbedaan yang cukup siginifikan antara ratarata peningkatan pemahaman kelompok eksperimen dengan faktor gain sebesar 0,51 dibandingkan dengan rata-rata peningkatan pemahaman kelompok kontrol dengan faktor gain sebesar 0,45 yang diperoleh dari skor tes awal dan tes akhir kedua kelompok. 
Hasil penelitian yang diperoleh, menunjukkan peningkatan pemahaman konsep pengukuran belum tercapai secara maksimal dilihat dari belum tercapainya ketuntasan klasikal hasil tes akhir siswa. Agar efektivitas dan efisiensi pembelajaran dengan media peraga ikonik tercapai secara maksimal, hendaknya guru dapat menambahkan media peraga ikonik dalam bentuk cetak dalam pembelajaran.

\section{UCAPAN TERIMA KASIH}

Ucapan terima kasih diucapkan kepada kepala SMP Negeri 1 Banjarharjo yang telah mendukung penelitian ini.

\section{DAFTAR PUSTAKA}

Aminulloh, A. M., \& Widodo, W. Keefektifan Alat Peraga Bunyi untuk Meningkatkan Motivasi Belajar dan Pemahaman Konsep Siswa. Pensa: Jurnal Pendidikan Sains, 6(02), 134-140. Retrieved from https://jurnalmahasiswa.unesa.ac.id/index.ph $\mathrm{p} /$ pensa/article/view/23306

Fajriah, U. N., \& Churiyah, M. (2016). Utilizing Instructional Media for Teaching Infrastructure Administration. Journal of Education and Practice, 7(6), 100-111. Retrieved from https://eric.ed.gov/?id=EJ1092480

Firdaus, T. (2018). Pemanfaatan Media Berbasis Teknologi dalam Pembelajaran. https://doi.org/10.31219/osf.io/46cki

Hadi, S. (2017). Efektivitas Penggunaan Video Sebagai Media Pembelajaran Untuk Siswa Sekolah Dasar. In Seminar Nasional Teknologi Pembelajaran dan Pendidikan Dasar 2017, 96-102. Retrieved from http://pasca.um.ac.id/conferences/index.php/ sntepnpdas/article/view/849

Misbah, D., Surya, M., \& Maskur, M. (2017). Penggunaan Media Audio Visual dalam Pembelajaran yang Berbasis Power Point Model Pop Up untuk Meningkatkan Hasil Belajar Siswa pada Materi Kosakata Mata Pelajaran Bahasa Arab. Teknologi Pembelajaran, 2(2), 404-417. Retrieved from https://journal.institutpendidikan.ac.id/index.p hp/tekp/article/view/144

Mulyasa. (2002). Kurikulum Berbasis Kompetensi (Konsep, Karakteristik, dan Implementasi). Bandung: PT. Remaja Rosdakarya.

Mu'min, A. N., Sarwi, S., \& Akhlis, I. (2015). Efektivitas Pembelajaran Kontekstual Berbantuan Media Simulasi Virtual Untuk Meningkatkan Pemahaman Konsep Dan Minat Belajar. UPEJ Unnes Physics Education Journal, 4(3), 65-72. https://doi.org/10.15294/upej.v4i3.9979

Riyanti, G. A., Sutikno, S., \& Masturi, M. (2015, October). Penerapan Alat Peraga SeriParalel DC untuk Meningkatkan Pemahaman Siswa pada Materi Hukum OHM. In Prosiding Seminar Nasional Fisika UNJ, 4, 129-134. Retrieved from http://journal.unj.ac.id/uni/index.php/prosidin gsnf/article/view/4683

Sugiyono. (2016). Metode Penelitian Pendidikan. Bandung: Alfabeta.

Widodo, W., Rachmadiarti, F., dan Hidayatai, S.N. (2016). IImu Pengetahuan Alam untuk Siswa SMP kelas VII semester 1. Jakarta: Kemendikbud.

Wiyanto. (2008). Menyiapkan Guru Sains Mengembangkan Kompetensi Laboratorium. Semarang: Universitas Negeri Semarang Press. 